\title{
A incorporação da responsabilidade social e sustentabilidade: um estudo baseado no relatório de gestão 2005 da companhia paranaense de energia - COPEL
}

\author{
Sustainability business: a study based on the 2005 report \\ of the Paraná state energy management company - COPEL
}

\author{
Luci Ines Bassetto'
}

\begin{abstract}
Resumo: O presente trabalho trata dos conceitos e práticas da Responsabilidade Social e Sustentabilidade Empresarial. Estabeleceu-se como objetivo geral demonstrar como a COPEL está inserindo tais práticas em sua gestão da Responsabilidade Social e Sustentabilidade. Neste sentido, foram propostos os seguintes objetivos específicos: a) Identificar e caracterizar os indicadores e relatórios de prestação de contas utilizados na empresa COPEL para medir e apresentar os resultados de sua gestão sustentável; b) Identificar e analisar as ações sustentáveis executadas pela empresa. Como instrumento de análise adotou-se o Relatório de Gestão de 2005. A análise indicou um grande esforço da COPEL no sentido de inserir-se como empresa de Responsabilidade Social incorporando o conceito do Instituto Ethos para desenvolvimento de seu modelo de gestão. E, como empresa sustentável, implementando ações por meio das seguintes plataformas: como signatária do Pacto Global; como empresa sustentável por meio do ISE- BOVESPA 2005, adoção de alguns princípios dos Objetivos do Milênio e Norma AA 1000. O principal indicador utilizado para a análise foi a GRI adotada na forma "de acordo". Ao atender a todos os princípios da GRI para elaboração de Relatório, a análise indicou que, embora sendo o primeiro Relatório, a COPEL encontra-se em estágio bem avançado na implementação de indicadores. Para um ambiente que requer que o resultado econômico seja obtido da integração de ações sociais e ambientais, os dados coletados a respeito, da forma como estão apresentados, não permitiram identificar a integração das ações sociais e ambientais ao resultado econômico, sendo que as diretrizes da GRI (INSTITUTO ETHOS, 2002) não avançaram ainda para esse grau de detalhamento.
\end{abstract}

Palavras-chave: Indicadores. Responsabilidade social. Sustentabilidade.

\begin{abstract}
This work deals with the concepts and practices of Social Responsibility and Corporate Sustainability. The main goal of this study is to show how COPEL has been adopting such practices as part of its Social Responsibility and Sustainability management. In this sense, we proposed the following specific objectives: a) identify and characterize COPEL's indicators and accounting reports to measure and present the results of its sustainable management and b) Identify and analyze the sustainable actions performed by the company. The 2005 Management Report was used as an analysis tool. The analysis indicated COPEL's great deal of effort to meet social responsibility requirements by incorporating the concept of the Instituto Ethos Institute to develop its management model and, as sustainable business, implementing actions through the following platforms: as a signatory of the Global Compact, as a company sustainable through BOVESPA ISE-2005, and the adoption of certain principles of the Millennium Development Goals and AA 1000 standard. The main indicator used in the analysis was in accordance with the GRIs. By meeting all principles of GRI to prepare the report, although being the first report, the analysis indicated that COPEL is very advanced in terms of implementation of indicators. For an environment that requires that the economic result are obtained by integrating social and environmental actions, the data collected failed to identify the integration of social and environmental actions with the economic results since the guidelines GRI (INSTITUTO ETHOS, 2002) have not yet advanced to that degree of detail.
\end{abstract}

Keywords: Indicators. Social responsibility. Sustainability.

\section{Introdução}

Até a década de 1970, as políticas e ações econômicas se orientavam pelo uso intensivo dos

recursos, e se pautavam no aumento da produção, do consumo e da riqueza. A sustentação desse trip

\footnotetext{
${ }^{1}$ Universidade Tecnológica Federal do Paraná - UTFPR, Av. Monteiro Lobato, s/n, Km 04, CEP 84016-210, Ponta Grossa - PR, Brasil, E-mail: luciines@utfpr.edu.br
} 
era o desafio para o "desenvolvimento" da sociedade (SILVA; MENDES, 2005).

Durante a década de 1980 surgiu o termo sustentabilidade, originado de uma conscientização crescente de que os países precisavam descobrir maneiras de promover o crescimento de suas economias sem destruir o meio ambiente ou sacrificar o bem-estar das futuras gerações (SAVITZ; WEBER, 2007).

A Comissão Mundial sobre Meio Ambiente e Desenvolvimento (1991) foi criada em 1983, com a finalidade de reexaminar os problemas críticos do meio ambiente e desenvolvimento do planeta e formular propostas realistas para solucioná-los. O trabalho dessa comissão resultou na publicação de um relatório denominado Our Common Future (Nosso futuro comum) que registrava os sucessos e as falhas do desenvolvimento mundial.

O trabalho dessa Comissão aponta duas justificativas básicas para um desenvolvimento sustentável: em relação ao meio ambiente, controle dos danos gerados à biosfera pela intervenção humana, tendo como objetivo o uso racional dos recursos naturais; nas questões sociais, prioridade no que se refere às principais necessidades básicas das pessoas em todo o mundo no sentido de gerar oportunidades para o alcance de uma vida melhor.

Para essa Comissão, o desenvolvimento sustentável fundamenta-se no desejo de satisfazer as necessidades humanas presentes, sem comprometer a possibilidade das próximas gerações também satisfazerem as suas necessidades. Esse conceito torna-se a base para as organizações fundamentarem sua gestão, comprometida com a responsabilidade social.

Apesar de as economias poderem apresentar diferentes estruturas de produção e consumo, elas deverão estar centradas no objetivo comum, inerente ao conceito de desenvolvimento sustentável e nas estratégias necessárias para sua execução. Dessa forma, as empresas devem prestar contas, não só aos acionistas e credores, mas também a uma gama bem maior de interessados formando um público amplo identificado como stakeholders.

É nesse ambiente de negócios que a sustentabilidade passa a ser o grande desafio das empresas na busca de estratégia que as conceituem como uma empresa engajada nesse ambiente. Assim, sustentabilidade passa a significar gestão esclarecida e disciplinada que, a propósito, é o fator mais importante que os investidores levam em conta e devem ter em vista nas suas decisões de compra de ações.

Conforme António apud Buffara (2003), o momento atual aponta um novo contexto socioeconômicoambiental e uma nova responsabilidade a ser assumida. Assim, o papel social das organizações vem sendo redesenhando de forma mais ampla e abrangente, caracterizando-se como agentes de transformação e de influência na sociedade como um todo.
A postura proativa da empresa passa a envolver um processo em cadeia, no qual, todos os elos são corresponsáveis pela geração de novos produtos e processos, permitindo o passo à frente em direção ao desenvolvimento sustentável, última e mais desafiante estratégia.

A partir dos autores já citados, pode-se definir responsabilidade social como o compromisso que uma organização assume perante a sociedade por meio de atos e atitudes que a afetam positivamente, de modo amplo, ou a alguma comunidade, de modo específico, agindo proativa e coerentemente no que tange a seu papel específico na sociedade e a sua prestação de contas para com ela.

Tinoco e Kraemer (2004) entendem que o reconhecimento da dimensão social das empresas exige que sejam criados instrumentos de demonstração dos atos e valores relevantes para a sociedade ou para parceiros, da empresa (stakeholders) e não apenas dos resultados econômicos e financeiros.

Deste modo, para as empresas que adotam este procedimento, o Balanço Social e outros tipos de relatórios, devidamente auditados, permitem aos empresários e aos agentes sociais identificar, medir e agir sobre os fatos sociais vinculados à empresa, tanto interna quanto externamente. Com isso, nas empresas que divulgam relatórios de sustentabilidade, sua adoção é fato e não hipótese (INSTITUTO ETHOS, 2002).

Inserem-se neste contexto as concessionárias e permissionárias de energia elétrica, sendo estas básicas para o Sistema de Produção e de Consumo de toda uma economia. Como toda organização empresarial, estas empresas extraem do meio ambiente e social os recursos necessários à realização das suas atividades econômicas (insumos naturais, mão de obra, infraestrutura básica das cidades), e, ao realizarem os seus serviços, promovem mudanças sociais, econômicas, culturais e tecnológicas. A tomada de consciência da atuação e reflexos das suas atividades empresariais constitui a sua Responsabilidade Social.

No âmbito do Setor Elétrico, especialmente, por se tratar de um serviço público prestado sob o regime de concessão, a análise dessa responsabilidade deve ser ainda mais ampliada. Requer compreender que a prestação desses serviços tem de atender prioritariamente ao interesse público, já que toda concessão ou permissão pressupõe a prestação de um serviço adequado que satisfaça as condições de regularidade, continuidade, eficiência, segurança, atualidade, generalidade, cortesia e modicidade das tarifas, conforme dispõe a Lei $\mathrm{n}^{\circ} 8.987$ de 13 de fevereiro de 1995 sobre o regime de concessão e permissão da prestação de serviços públicos previsto no art. 175 da Constituição Federal de 1988.

Consciente dessa nova ordem social, a Companhia Paranaense de Energia (COPEL), empresa localizada no Estado do Paraná, vem, desde 1999, empreendendo 
esforços no sentido de aprofundar seu entendimento e incorporar o conceito de sustentabilidade em sua estratégia de negócios.

No sentido de contribuir para os estudos da prática da sustentabilidade, este trabalho objetivou demonstrar como a COPEL está incorporando a sustentabilidade em sua gestão, tendo como objetivos específicos:

- Identificar e caracterizar os indicadores e relatórios de prestação de contas utilizados na empresa COPEL para medir e apresentar os resultados de sua gestão sustentável; e

- Identificar e analisar as ações sustentáveis executadas pela empresa.

Dos procedimentos metodológicos, definiu-se a pesquisa exploratória e descritiva, com abordagem qualitativa, responsáveis pela revisão bibliográfica. Para a pesquisa de campo, aplicou-se o estudo de caso na COPEL, reconhecida como empresa que tem empreendido esforços para enquadrar-se como empresa sustentável.

A coleta dos dados deu-se por meio de contatos e conversas informais com a gerência do Setor de Responsabilidade Social da COPEL, no período entre novembro de 2006 a abril de 2007. E, para a análise do objeto de estudo, utilizou-se o Relatório de Gestão 2005, elaborado com base nos indicadores da Global Reporting Initiative (INSTITUTO ETHOS, 2002).

\section{A responsabilidade social das empresas no desenvolvimento sustentável}

Para o livre exercício da atividade produtora de bens e serviços, as empresas deverão observar vários fatores, que, dentre os principais, destacam-se: a) a livre concorrência; b) defesa do consumidor; c) a defesa do meio ambiente; d) a redução das desigualdades sociais regionais; e e) a oferta de emprego (LEWIS, 2005).

Assim, do poder emanado constitucionalmente ao empreendedor de exercer livremente sua atividade emana, também, o dever de utilizá-la em prol da sociedade. Deve a empresa, portanto, visar, além dos lucros e da produção de bens, atender sua função de servir a sociedade como um todo (REALE, 1998 apud LEWIS, 2005).

Neste contexto, as empresas assumem papel de agentes transformadores da sociedade, imbuídas de responsabilidade em desenvolver ações que visem a dignidade humana, sem recorrer a ações que possam prejudicar o seu público, seus clientes, seus fornecedores e a sociedade em que está estabelecida. Para tanto, é necessário a empresa precaver-se de recursos financeiros e patrimoniais no sentido de garantir o desempenho dos negócios e cumprimento de suas obrigações monetárias.
O aspecto jurídico da responsabilidade social das empresas, no Brasil, encontra a base na Constituição Federal de 1988 disposta no artigo 170, e seguintes, os quais citam os princípios gerais da atividade econômica, garantindo a livre iniciativa mediante uma contraprestação da empresa, a qual deverá participar da integração do cidadão à coletividade, garantindo-lhe bem-estar e uma existência digna. No artigo $5^{\circ}$, caput e incisos XII e XXIII, a referida Constituição estabelece que todos são iguais perante a lei, à igualdade, à segurança e à propriedade, mas indicando que ela atenderá à sua função social.

Para Savitz e Weber (2007), o termo sustentabilidade se transformou em assunto de amplas discussões sociais e ambientais, sobretudo no mundo dos negócios e denota uma ideia poderosa e objetiva: empresa sustentável é aquela que gera lucro para os acionistas, ao mesmo tempo em que protege o meio ambiente e melhora a vida das pessoas com que mantém interações.

As evidências da necessidade de que as organizações, para a sua sobrevivência, devem adotar, em sua gestão, práticas de sustentabilidade, requerem formas de análise dos impactos das atividades empresariais em relação às questões econômicas, sociais e ambientais e os efeitos dessas práticas sobre o lucro.

Aplicada na prática, a sustentabilidade envolve estratégia, gestão e lucro. As dimensões econômicas sociais e ambientais geram riscos e oportunidades que estão mudando profundamente os setores de atividades e os negócios em geral (SAVITZ; WEBER, 2007).

Um modelo de gestão empresarial baseado em três pilares - viabilidade econômica, consciência ambiental e responsabilidade social - consiste no conceito inglês de Tríplice Resultado ou Triple Bottom Line (TBL) e indica que todo negócio é alicerçado pelos três pilares (o econômico, o ambiental e o social) que são inter-relacionados e devem ser integrados à estratégia de negócios. Segundo esse conceito, o progresso sustentável a longo prazo requer o equilíbrio desses parâmetros.

Também é conhecido como o modelo de gestão dos três Ps: People, Planet e Profit, sendo People - pessoas direta e indiretamente envolvidas; Planet - meio ambiente e impactos; e Profit - retorno financeiro.

O TBL, segundo Elkington apud Savitz e Weber (2007), sugere que as empresas avaliem o sucesso não só com base no desempenho financeiro, mas também sob o ponto de vista de seu impacto sobre a economia mais ampla, sobre o meio ambiente e sobre a sociedade em que atua. Quando positivo reflete o aumento no valor da empresa, tanto na lucratividade e geração de riqueza para os acionistas quanto sob o aspecto de seu capital social, humano e ambiental. 


\section{Indicadores de sustentabilidade}

\subsection{Plataformas de gestão}

Não há apenas um modelo padronizado de avaliação de estratégias para a sustentabilidade, a exemplo das Demonstrações Contábeis. Assim, além da publicação anual dos balanços e relatórios sociais e ambientais, ganham destaques as certificações, selos e standards internacionais na área social. No Brasil, os principais exemplos são: Selo Empresa Amiga da Criança, conferido pela Fundação Abrinq; o Selo Empresa Cidadão, prêmio instituído pela Câmara Municipal da cidade de São Paulo; e o Selo Balanço Social Ibase/ Betinho, do Instituto Brasileiro de Análises Sociais e Econômicas desde 1998 (BUFFARA, 2003).

Há também, a premiação oferecida anualmente pelo Instituto Ethos, que consiste no seguinte:

- O Prêmio Instituto Ethos-Valor, voltado para estudantes universitários;

- O Prêmio Instituto Ethos de Jornalismo, dirigido a jornalistas; e

- O Prêmio Balanço Social, para empresas (INSTITUTO ETHOS, 2008).

No cenário internacional, algumas iniciativas se destacam, a exemplo do denominado Global Compact (Pacto Global), que busca o apoio e a adesão dos países a um pacto com o objetivo de promover uma economia global inclusiva e sustentável.

Trata-se de uma iniciativa no sentido de mobilizar a comunidade empresarial internacional para a promoção de valores fundamentais nas áreas de direitos humanos, trabalho e meio ambiente. Para tanto, conta com a participação das agências das Nações Unidas, empresas, sindicatos, organizações não governamentais e demais parceiros necessários para a construção de um mercado global mais inclusivo e igualitário (INSTITUTO ETHOS, 2006).

O Pacto Global constitui-se de centenas de organizações nacionais e internacionais, sendo 230 organizações brasileiras signatárias. Dessas, 79 são reconhecidas no site mundial do Pacto Global. As demais se encontram em processo de reconhecimento. Para serem consideradas "signatárias" pelo escritório mundial do Global Compact, as organizações devem encaminhar carta ao atual Secretário-Geral Ban Ki-moon juntamente com sua Folha de Dados (INSTITUTO ETHOS, 2007).

O Pacto Global defende dez princípios universais, derivados da Declaração Universal de Direitos Humanos, da Declaração da Organização Internacional do Trabalho sobre Princípios e Direitos Fundamentais no Trabalho, da Declaração do Rio sobre Meio Ambiente e Desenvolvimento e da Convenção das Nações Unidas Contra a Corrupção (INSTITUTO ETHOS, 2007).

\subsection{Normas}

Outras iniciativas compreendem as normas nacionais e internacionais, que assumem papel relevante uma vez que buscam sistematizar ações necessárias para a incorporação de um sistema de gestão da Responsabilidade Social Corporativa nas operações rotineiras da empresa. Dentre elas, constam a Norma Accountability [AA (1000)] lançada em 1999 , que define as práticas para prestação de contas com o objetivo de assegurar a qualidade da contabilidade, auditoria e relato social ético.

Pode ser usada isoladamente ou em conjunto com outros padrões de prestação de contas tais como a Global Report Initiative (GRI), e normas padrões como a International Organization for Standardization (ISO) e a Social Accountability [SA (8000)]. Visa auxiliar diversos usuários, tais como empresas, acionistas, auditores, consultores e organizações certificadoras. Uma das mais importantes contribuições da AA 1000 são os processos e definições que dão suporte à prática da responsabilidade social empresarial (INSTITUTO ETHOS, 2005).

A Norma Social Accountability (SA 8000) é uma norma certificadora de responsabilidade social baseada nas normas da Organização Internacional do Trabalho (OIT), na Declaração Universal dos Direitos Humanos e na Declaração Universal dos Direitos da Criança.

A SA 8000 tem a preocupação de coibir a prática de trabalho infantil e escravo e outras práticas de contratação de empregados consideradas abusivas, abordagem essa, mais restrita em relação à AA 1000. Essa contém um princípio de inclusividade e um processo em que a própria organização deve identificar as partes interessadas relativas ao seu negócio, o que a difere da SA 8000 (ORIBE, 2007).

Para manter as certificações, os treinamentos são essenciais, uma vez que eles disseminam os conhecimentos dos padrões entre os funcionários e ensinam gerentes a usar melhor a ferramenta. (INSTITUTO ETHOS, 2005).

A ABNT NBR série 16000 é uma norma brasileira voltada para a gestão da responsabilidade social com foco na melhoria da organização. Estabelece os requisitos mínimos relativos a um sistema da gestão da responsabilidade social, permitindo à organização formular e implementar políticas e objetivos que levem em conta requisitos legais e outros, seus compromissos éticos e sua preocupação com a promoção da cidadania; a promoção do desenvolvimento sustentável; e a transparência das suas atividades (ASSOCIAÇÃO BRASILEIRA DE NORMAS TÉCNICAS, 2004).

Segundo Bezerra (2007), esta Norma tem por objetivo prover às organizações os elementos de um sistema da gestão da responsabilidade social eficaz, passível de integração com outros requisitos de gestão, de forma a auxiliá-las a alcançar seus objetivos 
relacionados com os aspectos da responsabilidade social.

As normas assumem uma grande importância pelo fato de apoiar a sistematização de ações necessárias à incorporação de um sistema de Gestão de Responsabilidade Social Empresarial.

Da abreviação International Organization for Standardization (ISO), são padrões que visam contribuir para as áreas de desenvolvimento, produção e suprimento das empresas, com o objetivo de tornar o processo mais eficiente, seguro e limpo.

Dentre as mais conhecidas estão as séries ISO 9000 e ISO 14000. A primeira refere-se a padrões em qualidade total, e a segunda, direcionada para padrões de proteção ambiental.

Os padrões ISO estão sendo adotados por milhares de organizações e em centenas de países.

Tais padrões servem como ferramentas para engenheiros e industriais, na solução de problemas relacionados à distribuição, com a finalidade de garantir aos consumidores e usuários produtos e serviços de qualidade.

Outra vantagem da adoção desses padrões é que eles facilitam as negociações entre países, suprem os governos com bases técnicas para saúde, segurança e legislação ambiental e auxiliam na transferência de tecnologia para os países em desenvolvimento. Podem ser adotados tanto no setor privado quanto no público, ou em órgãos governamentais (INSTITUTO ETHOS, 2005).

\subsection{Indicadores}

O termo indicador é expressão do latim indicare, que significa descobrir, apontar, anunciar, estimar. Nas ciências ambientais, indicador significa um organismo, uma comunidade biológica ou outro parâmetro (físico, químico, social) que serve como medida das condições de um fator ambiental, ou um ecossistema (BITTENCOURT, 2006).

Para a Organização para a Cooperação e Desenvolvimento Econômico (OCDE), um indicador deve ser entendido como um parâmetro, ou valor derivado de parâmetros que apontam e fornecem informações sobre o estado de um fenômeno, com uma extensão significativa (ORGANIZATION FOR ECONOMIC COOPERATION AND DEVELOPMENT, 1993).

\subsection{Relatórios}

Relatórios econômico, social e ambiental são meios que as empresas adotam para relatar e divulgar seu desempenho para todos aqueles que se interessam por esse tipo de informação, tais como seus parceiros sociais, permitindo-lhes entender seu relacionamento com a empresa reportada (TINOCO; KRAEMER, 2004).
Conforme o Instituto Ethos (2006), há três modelos-padrão de balanço social: dois nacionais propostos pelo Instituto Brasileiro de Análises Sociais e Econômicas (Ibase) e pelo Instituto Ethos - e um internacional, sugerido pela Global Reporting Initiative (GRI). Tais modelos visam definir as informações mínimas que devem ser publicadas para dar transparência às atividades da empresa. As organizações têm a liberdade de adotar um formato próprio definido, em geral, pela área de comunicação da companhia.

Quanto ao Modelo Ibase, lançado em 1997, pelo Ibase, inspira-se no formato dos balanços financeiros e expõe, de maneira detalhada, os números associados à responsabilidade social da organização. Em forma de planilha, reúne informações sobre a folha de pagamentos, os gastos com encargos sociais de funcionários, a participação nos lucros. Também detalha as despesas com controle ambiental e os investimentos sociais externos nas diversas áreas educação, cultura, saúde, etc.

O Modelo Instituto Ethos é baseado num relato detalhado dos princípios e das ações da organização, incorpora a planilha proposta pelo Ibase e sugere um detalhamento maior do contexto da tomada de decisões, dos problemas encontrados e dos resultados obtidos. O Instituto Ethos defende a necessidade de os balanços sociais adquirirem credibilidade e consistência comparáveis às dos balanços financeiros, verificando os seguintes princípios: relevância, veracidade, clareza, comparabilidade, regularidade e verificabilidade.

O Instituto Ethos (2006) sugere que o Balanço Social contemple o resultado tríplice com os seguintes conteúdos: indicadores de desempenho econômico, indicadores de desempenho social e indicadores de desempenho ambiental.

O modelo internacional Global Reporting Initiative (GRI) para a Apresentação de Relatórios ganha cada vez mais importância. Sua estrutura centra-se em dois pontos: comparabilidade e flexibilidade, sendo que a primeira liga-se à meta de desenvolver uma estrutura paralela aos relatórios financeiros. A segunda considera as diferenças legítimas entre organizações e entre setores da economia, atuando de modo flexível o suficiente para acomodar essas diferenças.

A GRI estabelece princípios essenciais para a elaboração de relatórios equilibrados e abrangentes sobre o desempenho econômico, ambiental e social de uma organização e esses representam metas que os elaboradores tentam atingir e também devem ser aplicados pelas organizações na elaboração de seus relatórios. 
Os princípios norteadores para elaboração dos relatórios de sustentabilidade expostos pela GRI são visualizados na Figura 1.

A adoção desses princípios pode apresentar as seguintes vantagens: visão abrangente do desempenho econômico, ambiental e social da organização, descrevendo a contribuição da organização ao desenvolvimento sustentável; comparar desempenhos ao longo do tempo e entre organizações distintas; e, imagem de credibilidade dos assuntos importantes para as partes interessadas (INSTITUTO ETHOS, 2002).

Organizada sob o conceito conhecido como triple bottom line, ou tríplice resultado, as Diretrizes da GRI (INSTITUTO ETHOS, 2002) entendem a sustentabilidade baseada no equilíbrio nas relações atuais entre necessidades econômicas, ambientais e sociais sem comprometer o desenvolvimento futuro.

No entanto, a GRI reconhece que, como toda simplificação de conceitos complexos, esta definição tem suas limitações. Ela pode constituir, em alguns casos, a noção de que cada esfera deva ser analisada isoladamente antes de uma abordagem integrada. Mesmo assim, a definição do tipo "resultado triplo" atingiu um certo consenso como uma boa abordagem inicial para um assunto complexo (INSTITUTO ETHOS, 2002).

Segundo a GRI (INSTITUTO ETHOS, 2002), há duas formas de se utilizar as diretrizes: como uma referência informal ou então incorporá-las de forma progressiva e, ou num nível mais exigente, denominado "de acordo com". Esse nível se baseia na transparência para adequar as particularidades de cada relatório com o objetivo de aumentar a comparabilidade de informações, visto que os indicadores econômicos, ambientais e sociais são tratados individualmente na matriz da GRI.

Quanto ao Índice de Sustentabilidade Empresarial (ISE) - BOVESPA é resultado de esforços de várias instituições - ABRAPP, ANBID, APIMEC, IBGC, IFC, Instituto Ethos e Ministério do Meio Ambiente no sentido de torná-lo referencial (benchmark) para os investimentos socialmente responsáveis.

O ISE tem por objetivo refletir o retorno de uma carteira composta por ações de empresas com reconhecido comprometimento com a responsabilidade social e a sustentabilidade empresarial, e também atuar como promotor das boas práticas no meio empresarial brasileiro.

O conceito-base do ISE é o do triple bottom line (TBL), introduzido pela empresa de consultoria inglesa SustainaAbility, que avalia elementos econômicofinanceiros, sociais e ambientais de forma integrada. Aos princípios do TBL, foram acrescentados critérios e indicadores de governança corporativa, seguindo o modelo do índice da Bolsa de Johannesburg, o que deu origem a um quarto grupo temático.

Os quatro blocos são precedidos por um grupo de indicadores gerais básicos e de natureza do produto. Entre estes indicadores gerais e de natureza do produto incluem-se, por exemplo, se a companhia publica Balanço Social ou de Sustentabilidade, se endossou o Pacto Global da ONU e se o consumo ou utilização dos produtos da companhia acarretam danos efetivos ou riscos à saúde, integridade física ou segurança dos consumidores, de terceiros, ou ainda relacionados à saúde e segurança públicas.

No questionário do ISE, a esses princípios de TBL foram acrescidos mais dois grupos de indicadores: a) critérios gerais e de natureza do produto (que

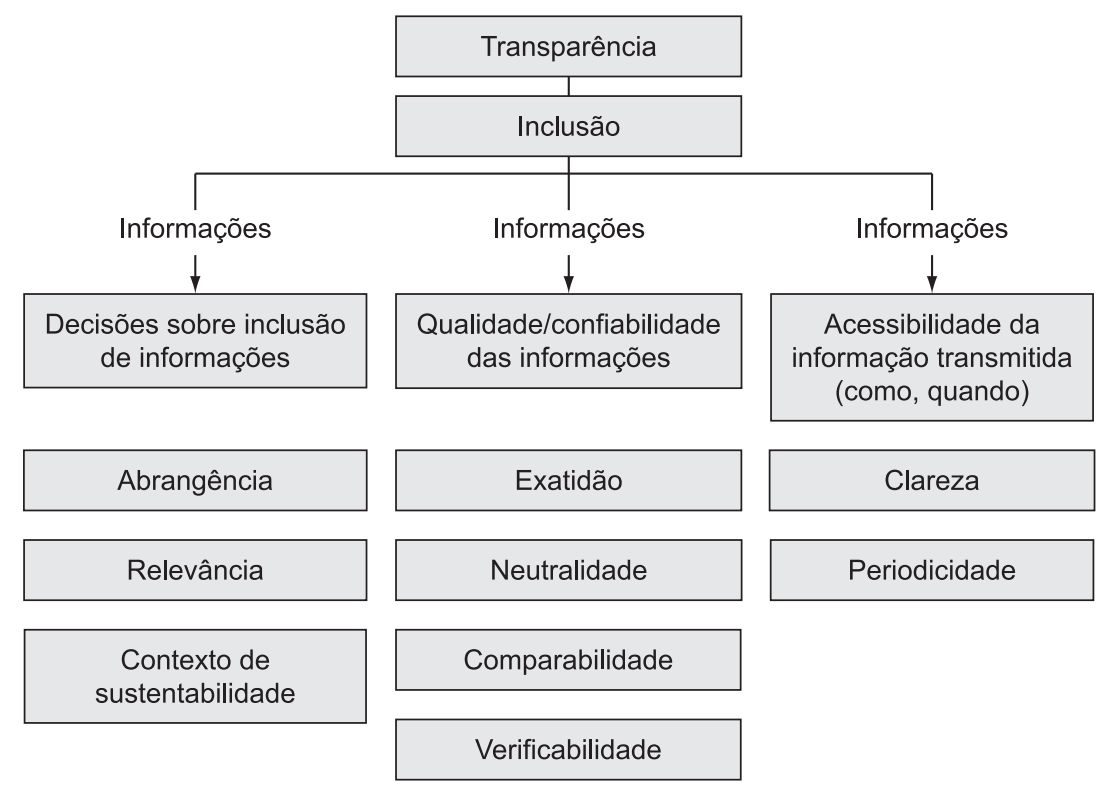

Figura 1. Princípios para Relatórios. Fonte: Instituto Ethos, 2002. 
questiona, por exemplo, a posição da empresa perante acordos globais, se a empresa publica balanços sociais, se o produto da empresa acarreta danos e riscos à saúde dos consumidores, entre outros); e b) critérios de governança corporativa.

As respostas das companhias são analisadas por uma ferramenta estatística chamada "análise de clusters", que identifica grupos de empresas com desempenhos similares e aponta o grupo com melhor desempenho geral. As empresas desse grupo irão compor a carteira final do ISE (que terá um número máximo de 40 empresas), após aprovação do Conselho.

O questionário do ISE será objeto de constante aprimoramento (o índice terá revisão anual, quando as empresas serão avaliadas novamente), com vistas a atender permanentemente às demandas contemporâneas da sociedade.

\section{Análise dos dados coletados}

\subsection{Caracterização da empresa estudada}

Este item apresenta os estudos da prática da sustentabilidade, da empresa COPEL, tendo como objetivos específicos:

- Identificar e caracterizar os indicadores e relatórios de prestação de contas utilizados na empresa COPEL para medir e apresentar os resultados de sua gestão sustentável; e

- Identificar e analisar as ações sustentáveis executadas pela empresa.

A COPEL consta como empresa pioneira do setor de energia elétrica a adotar a gestão sustentável fato considerado pertinente para a elaboração deste estudo. Seu crescimento está atrelado à sua atuação ética, responsável e realizadora, e a Política de Sustentabilidade e Cidadania Corporativa implementada na empresa deverá guiar todas as suas decisões e ações buscando sustentabilidade interna, respeito a todas as partes interessadas e ampla promoção da diversidade e da ética na condução dos negócios. Foi criado também, como complemento à política, um Código de Conduta da Companhia e ambos incluem em seu escopo os princípios do Pacto Global (COPEL, 2006).

No que se refere à Responsabilidade social empresarial, a COPEL adotou o conceito do Instituto Ethos para desenvolvimento de seu modelo de gestão.

Em termos internacionais, a COPEL assumiu seu compromisso com os stakeholders ao criar sua Política de Sustentabilidade, sendo uma das primeiras empresas brasileiras a adotar os princípios do Pacto Global, da ONU, em 2001.

A política de sustentabilidade da COPEL se baseia no tripé econômico, social e ambiental, e a adoção desses princípios garante, sob o ponto de vista econômico, a diminuição dos riscos estratégicos, operacionais e financeiros, aumentando o valor da Companhia e viabilizando a captação de recursos.

Socialmente, propicia a construção de uma sociedade mais equitativa. Do ponto de vista ambiental, possui programas e projetos ambientais integrados e prevê o custo da externalidade de suas atividades, comprometendo-se em deixar herança saudável para as gerações futuras.

Quanto ao planejamento estratégico, o modelo de gestão e planejamento empresarial integrado busca o alinhamento dos esforços para atingir e garantir, com base nos valores da COPEL e na gestão otimizada dos processos, o atendimento aos interesses das partes interessadas, bem como o desenvolvimento e o crescimento sustentável da Companhia.

Utilizando o Balanced Scorecard (BSC) como principal ferramenta, em dezembro de 2004, a Diretoria da COPEL aprovou um mapa que traduz uma hipótese estratégica para atingir a visão da Companhia, com 23 objetivos distribuídos em 5 perspectivas: sustentabilidade; financeira; cliente; processos internos e aprendizagem; e crescimento.

\subsection{Identificação e caracterização dos indicadores e relatórios utilizados pela Companhia Paranaense de Energia na gestão sustentável}

$\mathrm{O}$ atual posicionamento estratégico dá ênfase à produtividade, redução de custos e melhor utilização dos ativos no curto prazo, sem prejuízo, contudo, às ações que estimulem o crescimento da receita a médio e longo prazos. Os requisitos da Governança Corporativa e as práticas da COPEL evidenciam-se no Quadro 1.

Em 30/7/2002, o Presidente dos Estados Unidos assinou a Lei Sarbanes-Oxley (SOX), como uma forma de reação aos escândalos existentes no ambiente corporativo americano no ano anterior. Essa Lei reforça regras de governança corporativa relacionadas à divulgação e à emissão de relatórios financeiros. Um dos aspectos mais importantes é que a SOX não isenta empresas não americanas de seu alcance e exige que todas as companhias de capital aberto com ações listadas na Bolsa de Valores de Nova Iorque a ela se adaptem.

Para o ajuste à referida Lei, a COPEL tomou providências, de acordo com as exigências da SOX, mostradas no Quadro 2.

O Subcomitê de RSE validou o mapeamento dos stakeholders, nos moldes apresentados da AA 1000, com uma pequena adequação. Foi difícil classificar, de maneira rígida e exclusiva, alguns stakeholders em apenas uma das categorias (impactado, fortemente impactado, impactando e focado em valor). Para isso, adotou-se um modelo um pouco mais flexível, em que certos stakeholders são situados nas áreas de sombreamento correspondentes. 
Quadro 1. Comparativo entre os requisitos das Regras de Governança e a COPEL.

\begin{tabular}{|ccc|}
\hline Seção & $\begin{array}{c}\text { Regra de governança corporativa da bolsa } \\
\text { de Nova York para emissores americanos }\end{array}$ & Práticas da COPEL \\
\hline
\end{tabular}

303A.01 O conselho de administração da companhia listada deve ser majoritariamente composto por diretores independentes.

As companhias controladas não precisam cumprir essa exigência.

303A.03 Os conselheiros não-executivos de uma companhia listada devem comparecer a sessões executivas regularmente agendadas sem a presença da diretoria.

303A.04 Uma companhia listada deve possuir um comitê de governança corporativa e de nomeação composto, em sua totalidade, por diretores independentes, com um estatuto escrito que abordar certas obrigações específicas mínimas.

As companhias controladas não precisam cumprir essa exigência.

303A.05 Uma companhia listada deve apresentar um comitê de compensação composto inteiramente por diretores independentes, com um estatuto escrito que abordar certas obrigações específicas mínimas.

As companhias controladas não precisam cumprir essa exigência.

303A.06 Uma companhia listada deve possuir um 303A.07 comitê de auditoria com um mínimo de 3 (três) diretores independentes que satisfaçam os requisitos de independência da lei 10A-3 sob o Exchange Act, com um estatuto escrito que aborda certas obrigações específicas mínimas.

303A.08 Deve-se dar a oportunidade aos acionistas de votar em todos os planos de ações para funcionários e em todas as suas revisões matérias, exceto em ocasiões específicas determinadas nas regras da bolsa de Nova York.
A maioria dos membros do conselho de administração da COPEL são independentes, de acordo com o definido pelos padrões da bolsa de Nova York. A composição do conselho da COPEL cumpre com as exigências aplicáveis às companhias americanas que são companhias controladas. Não se requere que as companhias controladas tenham uma maioria de diretores independentes. A COPEL é uma companhia controlada, pois a maioria do poder de voto está sob controle do Estado do Paraná.

Os conselheiros não-executivos da COPEL comparecem a sessões regularmente agendadas, sem a presença da diretoria.

A COPEL não apresenta um comitê de governança corporativa e de nomeação. Como uma companhia controlada, a COPEL não precisaria cumprir a exigência de ter o comitê de governança corporativa e de nomeação se fosse uma companhia americana.

A COPEL não possui um comitê de compensação. Como uma companhia controlada, a COPEL não precisaria cumprir a exigência de ter comitê de compensação se fosse uma companhia americana.

Em junho de 2005, nossos acionistas alteraram nosso estatuto para estabelecer um comitê de auditoria composto de três conselheiros, com mandato de dois anos, podendo ser reeleitos. De acordo com o regimento interno do comitê de auditoria, os membros são indicados pelo conselho de administração e podem por ele ser substituídos. Os atuais membros do comitê são Acir Pepes Mezzadri, Rogério de Paula Quadros e Laurita Costa Rosa. Todos os membros do comitê de auditoria são membros de nosso conselho de administração.

O comitê de auditoria é responsável por nossas demonstrações contábeis, assegurando o cumprimento de todas as exigências legais relacionadas com as obrigações de divulgação, monitorando o trabalho dos auditores independentes e de nossa equipe encarregada da auditoria interna da companhia e revisando a eficácia dos procedimentos e pessoal de controle interno e de gerenciamento de riscos.

Sob a lei das S.A., a pré-aprovação dos acionistas é requerida para a adoção de qualquer plano de ações para funcionários. 
Quadro 1. Continuação.

\begin{tabular}{|c|c|c|}
\hline Seção & $\begin{array}{l}\text { Regra de governança corporativa da bolsa } \\
\text { de Nova York para emissores americanos }\end{array}$ & Práticas da COPEL \\
\hline 303A.09 & $\begin{array}{l}\text { Uma companhia listada deve adotar e divulgar } \\
\text { os princípios de práticas de governança } \\
\text { corporativa, os quais devem abordar certas } \\
\text { obrigações específicas mínimas. }\end{array}$ & $\begin{array}{l}\text { A COPEL não possui princípios formais de práticas de } \\
\text { governança corporativa que abordem todos os tópicos } \\
\text { especificados nas regras da bolsa de Nova York. }\end{array}$ \\
\hline 303A.10 & $\begin{array}{l}\text { Uma companhia listada deve adotar e } \\
\text { divulgar seu código de conduta e ética para } \\
\text { seus conselheiros, seus diretores e demais } \\
\text { empregados. Deve, também, apresentar } \\
\text { prontamente qualquer abdicação do código } \\
\text { para seus conselheiros ou diretores. }\end{array}$ & $\begin{array}{l}\text { A COPEL adotou um código de ética que se aplica } \\
\text { ao conselho de administração, ao conselho fiscal, } \\
\text { à diretoria e aos empregados. A COPEL publicará } \\
\text { qualquer abdicação das exigências do código para } \\
\text { conselheiros ou diretores no seu relatório 20-F. }\end{array}$ \\
\hline 303A. 12 & $\begin{array}{l}\text { O presidente de uma empresa listada deve } \\
\text { prontamente notificar a bolsa de Nova York, } \\
\text { por escrito, caso algum de seus diretores tome } \\
\text { conhecimento de qualquer descumprimento } \\
\text { material dos termos aplicáveis da seção 303A. }\end{array}$ & $\begin{array}{l}\text { O presidente da COPEL irá, prontamente, notificar } \\
\text { a bolsa de Nova York, por escrito, caso algum dos } \\
\text { diretores da COPEL tome conhecimento de qualquer } \\
\text { descumprimento material dos termos aplicáveis das } \\
\text { regras de governança corporativa da NYSE. }\end{array}$ \\
\hline
\end{tabular}

Fonte: COPEL, 2006.

Quadro 2. Exigências da SOX e medidas tomadas pela COPEL.

\begin{tabular}{|c|c|c|c|c|}
\hline Exigências SOX & $\begin{array}{c}\text { Prazo de } \\
\text { adaptação }\end{array}$ & Medidas adotadas pela COPEL & $\begin{array}{l}\text { Data de } \\
\text { adoção }\end{array}$ & $\begin{array}{c}\text { Informações } \\
\text { adicionais }\end{array}$ \\
\hline $\begin{array}{l}\text { Criação do comitê de } \\
\text { divulgação de atos e } \\
\text { fatos relevantes }\end{array}$ & - & $\begin{array}{l}\text { Instituído comitê de divulgação composto } \\
\text { por membros da presidência, diretoria } \\
\text { financeira, jurídica, controladoria, etc. }\end{array}$ & Jun./2002 & $\begin{array}{l}\text { Políticas de } \\
\text { divulgação e política } \\
\text { de negociação de } \\
\text { ações }\end{array}$ \\
\hline $\begin{array}{l}\text { Adoção de código de } \\
\text { conduta }\end{array}$ & - & $\begin{array}{l}\text { Adotado código de conduta, divulgado } \\
\text { aos empregados e disponibilizado no site } \\
\text { COPEL }\end{array}$ & Nov./2003 & Código de conduta \\
\hline $\begin{array}{l}\text { Criação do conselho } \\
\text { de orientação ética }\end{array}$ & - & $\begin{array}{l}\text { Instituído conselho composto por membros } \\
\text { de diversas áreas e presidido por membro } \\
\text { independente, da sociedade civil }\end{array}$ & Nov./2003 & $\begin{array}{l}\text { Conselho de } \\
\text { orientação ética }\end{array}$ \\
\hline $\begin{array}{l}\text { Criação do comitê } \\
\text { de auditoria ou } \\
\text { adaptação do } \\
\text { conselho fiscal }\end{array}$ & Jul./2005 & $\begin{array}{l}\text { Instituído comitê de auditoria composto } \\
\text { por } 3 \text { membros independentes do conselho } \\
\text { de administração }\end{array}$ & Jun./2005 & $\begin{array}{l}\text { Regimento interno } \\
\text { do comitê de } \\
\text { auditoria }\end{array}$ \\
\hline $\begin{array}{l}\text { Indicação de um } \\
\text { especialista em } \\
\text { finanças no comitê de } \\
\text { auditoria }\end{array}$ & Jul./2005 & $\begin{array}{l}\text { Escolhido, entre os membros do comitê de } \\
\text { auditoria, especialista em finanças }\end{array}$ & Jun./2005 & $\begin{array}{l}\text { Especialista } \\
\text { financeiro }\end{array}$ \\
\hline $\begin{array}{l}\text { Criação do canal de } \\
\text { comunicação (com } \\
\text { proteção a autores de } \\
\text { reclamações) }\end{array}$ & Jul./2005 & $\begin{array}{l}\text { Criado e divulgado entre os empregados } \\
\text { da COPEL um canal para recebimento de } \\
\text { reclamações }\end{array}$ & Jul./2005 & $\begin{array}{l}\text { Atribuições do canal } \\
\text { de comunicação } \\
\text { confidencial }\end{array}$ \\
\hline $\begin{array}{l}\text { Certificações } \\
\text { que atestam que } \\
\text { as informações } \\
\text { e controles da } \\
\text { companhia estão } \\
\text { corretos }\end{array}$ & Dez./2006 & $\begin{array}{l}\text { Com apoio de consultoria externa, } \\
\text { realizado mapeamento dos principais } \\
\text { processos que afetam as demonstrações } \\
\text { financeiras, e avaliados e documentados } \\
\text { riscos e controles internos relacionados. } \\
\text { A auditoria interna testa a eficácia desses } \\
\text { controles internos e verifica a existência de } \\
\text { planos de ação para correções/ajustes nos } \\
\text { casos pertinentes. }\end{array}$ & Dez./2005 & $\begin{array}{l}\text { Cronograma dos } \\
\text { trabalhos }\end{array}$ \\
\hline
\end{tabular}


Para maior clareza, a Figura 2 evidencia o mapeamento produzido e sugerido como melhoria para a norma.

Em 2005, a COPEL optou por publicar o primeiro relatório integrado atendendo aos requisitos da GRI. Além disso, a Agência Nacional de Energia Elétrica (ANEEL) e do Ibase fazem parte do relatório.

Os indicadores econômico-financeiros, ambientais e sociais abrangem a COPEL e suas Subsidiárias Integrais (Geração, Transmissão, Distribuição, Telecomunicações e Participações).

As demonstrações financeiras, incluindo o balanço social, englobam também o desempenho da Compagas e da Elejor, companhias nas quais a COPEL tem participação majoritária. Com o intuito de identificar as informações, a Companhia criou a matriz de localização dos indicadores GRI que, neste trabalho, foi identificada como matriz da GRI.

Segundo a Companhia, todos os princípios da GRI foram aplicados para essa edição do relatório. Os indicadores essenciais e adicionais não aplicáveis aos negócios da Companhia constam da matriz de localização e correlação como reprovados. Os indicadores cujas informações não estavam disponíveis em virtude da não realização de sua coleta de forma sistemática até então, foram tratados como meta para inclusão em relatórios futuros. Este relatório contém ainda, a correlação de seu conteúdo com os Princípios do Pacto Global.
Neste relatório adotou-se a divulgação do código de boas práticas de governança corporativa como sistema de gestão, e a utilização de indicadores sociais e ambientais, efetivamente na mesma plataforma dos econômico-financeiros.

A COPEL possui políticas, normas, manuais, especificações técnicas padronizadas, publicadas e disponíveis às respectivas partes interessadas, e auditáveis, seja por auditores internos ou externos. Os meios pelos quais as partes interessadas podem obter informações adicionais sobre os aspectos econômicos, ambientais e sociais da COPEL, bem como comentar ou sugerir melhorias para a próxima edição do relatório, estão relacionados nos itens Canais de diálogo e engajamento.

As ações da COPEL estão relacionadas com o disposto no artigo $6^{\circ}$ da Lei $n^{\circ} 8.987 / 95$ ao estabelecer que toda Concessão ou Permissão pressupõe a prestação de um serviço adequado que satisfaça as condições de regularidade, continuidade, eficiência, segurança, atualidade, generalidade, cortesia e modicidade das tarifas (VIEIRA, 2006).

Assim, a Resolução ANEEL n ${ }^{\circ}$ 444/2001 dispôs sobre a obrigatoriedade para as concessionárias e permissionárias, a partir de 2002, sofrendo mudança quanto a Elaboração do Relatório Anual de Responsabilidade Socioambiental das Empresas de Energia Elétrica por meio do Despacho SFF n ${ }^{\circ} 3.034$ de 21/12/2006 (VIEIRA, 2006).

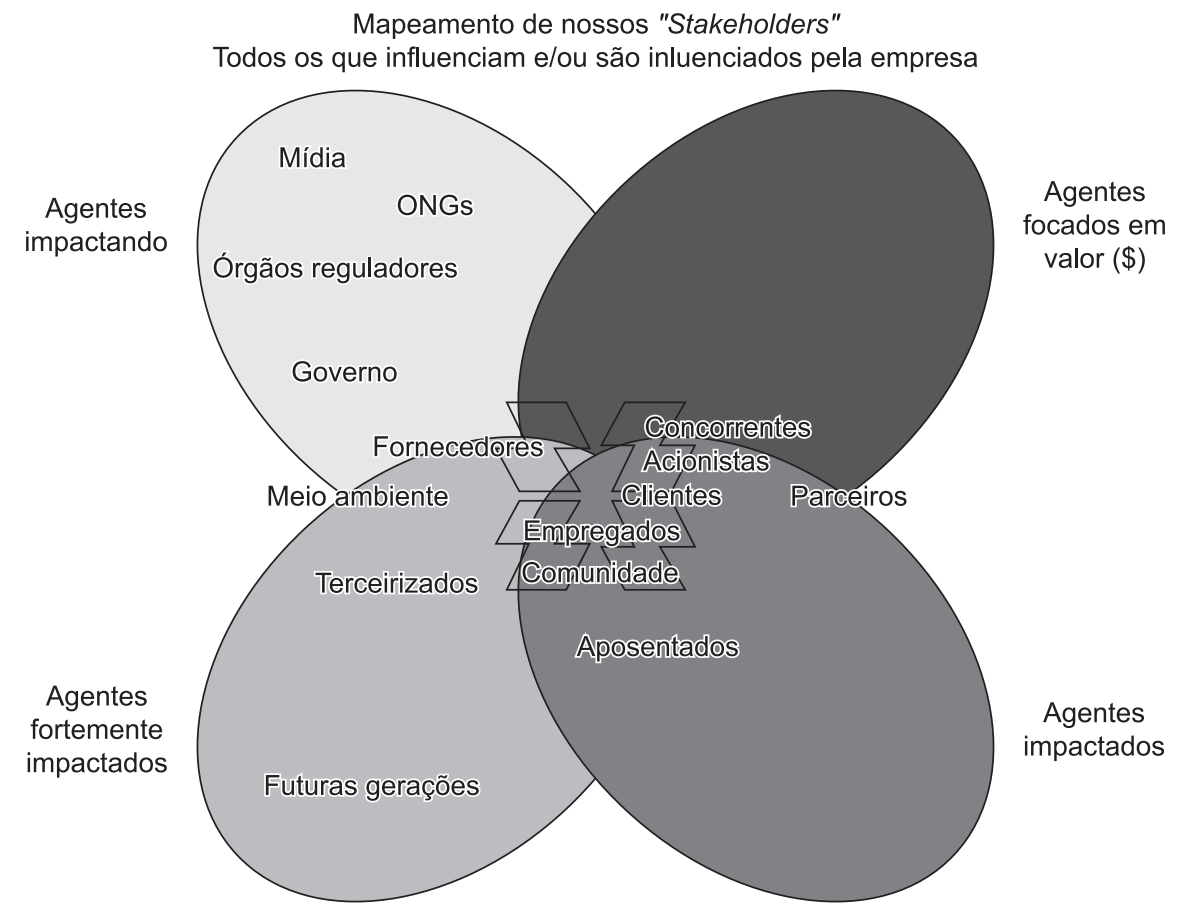

Figura 2. Mapeamento dos stakeholders da COPEL. Fonte: COPEL, 2006. 
Com relação ao ISE e às empresas que o comporiam, a Bovespa encaminhou questionário às companhias emissoras das 121 ações com maior liquidez da Bovespa e, selecionou, entre essas, 28. As ações ON (CPLE-3) e PNB (CPLE-6) da COPEL foram escolhidas para participar do índice, em sua primeira edição. A carteira do índice tem vigência de um ano, sendo reavaliada de acordo com os procedimentos e critérios integrantes da metodologia.

\subsection{Identificação e análise das ações sustentáveis executadas pela empresa Companhia Paranaense de Energia}

Embora o relatório seja identificado por Relatório de Gestão 2005, nele estão incorporadas as Demonstrações Contábeis exigidas pela Lei 6.404/76: Balanço Patrimonial, Demonstração de Resultados, Demonstração das Mutações do Patrimônio Líquido, Demonstração das Origens e Aplicações de Recursos, Demonstração do Valor Adicionado, Notas Explicativas às Demonstrações Contábeis. Além dessas, outras não obrigatórias se inserem no Relatório: A Demonstração do Fluxo de Caixa.

O Quadro 3 evidencia, de forma resumida, as ações estratégicas da COPEL de Responsabilidade Social para um sistema de Gestão para Sustentabilidade.

Percebe-se no item 1 que a empresa em análise tem inserido os itens necessários para uma formulação estratégica; quanto ao item 2, o Triple Bottom Line refere-se ao conceito de que todo negócio é alicerçado

Quadro 3. Práticas para gestão estratégica quanto à sustentabilidade.

\begin{tabular}{|lccc|}
\hline \multicolumn{1}{|c}{ Práticas para gestão } & \multicolumn{3}{c|}{ COPEL } \\
\cline { 2 - 5 } estratégica & \multicolumn{3}{c|}{$\begin{array}{c}\text { Demonstra } \\
\text { incorporação }\end{array}$} \\
\hline \multicolumn{1}{|c|}{ De acordo com a GRI } & Sim & Não & Em curso \\
\hline 1 Valores, transparência e & - & - & - \\
governança & & & \\
1.1.1 Visão e estratégia & $\times$ & - & - \\
1.1.2 Perfil & $\times$ & - & - \\
1.1.3 Estrutura de governança & $\times$ & - & - \\
e sistemas de gestão & & & \\
1.1.4 Sumário de & $\times$ & - & - \\
conteúdo da GRI & & & \\
2 Indicadores de desempenho & - & - & - \\
2.1 Tríplice resultado - TBL & - & - & - \\
2.1.1 Resultado econômico & $\times$ & - & - \\
2.1.2 Resultado ambiental & $\times$ & - & - \\
2.1.3 Resultado social & $\times$ & - & - \\
2.2 Integra as dimensões & - & - & $\times$ \\
\hline
\end{tabular}

Fonte: Autoria. pelos três pilares: o econômico, o ambiental e o social, que são inter-relacionados e devem ser integrados à estratégia de negócios.

Observando-se as Diretrizes da GRI de 2002, pode-se observar que a própria não adota esse comprometimento. Dessa forma, ações sociais e ambientais ficam limitadas a relatórios de ações, sem medir seu impacto no resultado da empresa.

A COPEL adotou a elaboração do relatório na forma de acordo com o que faz dela uma empresa comprometida com a Sustentabilidade.

O Quadro 4 evidencia os princípios da GRI.

A empresa empenhou esforços no sentido de absorver no Relatório de 2005, todos os princípios da GRI. Constata-se que, ao analisar o conteúdo dos princípios, alguns deles ainda não foram empregados na sua totalidade. É o caso da abrangência, exatidão, comparabilidade e periodicidade. Alguns deles necessitam de parâmetros, constantes no Relatório de Gestão 2006, que até a data dessa análise ainda não foram divulgados. Os indicadores essenciais e adicionais não aplicáveis aos negócios da Companhia constam da matriz de localização e correlação como reprovados.

Como a GRI (INSTITUTO ETHOS, 2002) adota, na sua essência, os princípios do Pacto Global, percebe-se neste aspecto um grande avanço na forma de divulgação: o relatório contém a correlação de seu conteúdo com os Princípios do Pacto Global. Isto indica que a grande plataforma de Sustentabilidade da COPEL é de forma global.

Quadro 4. Práticas para gestão estratégica - princípios da GRI.

\begin{tabular}{|lccc|}
\hline \multicolumn{1}{|c}{ Práticas para gestão } & \multicolumn{3}{c|}{ COPEL } \\
\cline { 2 - 5 } estratégica & \multicolumn{3}{c|}{$\begin{array}{c}\text { Demonstra } \\
\text { incorporação }\end{array}$} \\
\hline \multicolumn{1}{|c|}{ De acordo com a GRI } & Sim & Não & Em curso \\
\hline Princípios & - & - & - \\
Transparência & $\times$ & - & - \\
Inclusão & $\times$ & - & - \\
Verificabilidade & $\times$ & - & - \\
Abrangência & $\times$ & - & $\times$ \\
Relevância & $\times$ & - & - \\
Contexto de & $\times$ & - & - \\
sustentabilidade & $\times$ & & \\
Exatidão & & & $\times$ \\
Neutralidade & $\times$ & - & - \\
Comparabilidade & $\times$ & - & $\times$ \\
Clareza & $\times$ & - & $\times$ \\
Periodicidade & $\times$ & - & - \\
\hline Fonte: Autoria & $\times$ & - & $\times$ \\
\hline
\end{tabular}

Fonte: Autoria. 
A COPEL, além de utilizar os padrões da GRI, no âmbito internacional, foi escolhida para representar a América do Sul no grupo de trabalho da GRI, encarregado de formular diretrizes para a elaboração de Relatórios de Sustentabilidade no setor de energia elétrica.

Embora vários conceitos de Sustentabilidade tenham sido abordados nesse trabalho, é necessário ressaltar que, ainda que tenha o mesmo foco, cada um tem a sua particularidade.

O Quadro 5 mostra se as metodologias são incorporadas pela empresa.

Quanto aos Objetivos do Milênio, a COPEL divulga que participa do projeto "Fome Zero" do Governo Federal.

O Pacto Global é incorporado na íntegra, uma vez que a GRI o incorpora como base de seu conteúdo. Sob esse aspecto, a COPEL é signatária do Pacto Global da ONU - Global Compact. Isto quer dizer que a empresa assinou acordo comprometendo-se a estimular a prática e a disseminação dos dez princípios ligados a direitos humanos, trabalho, meio ambiente e combate à corrupção.

A Norma AA 1000 foi implantada e sua conclusão está prevista para 2008, quando as auditorias externas ontemplarão a auditagem do sistema de sustentabilidade de forma integrada. Já as Normas ISO 9000 e 14000, não constam no Relatório.

Em 2005, a COPEL atendeu aos requisitos para o ISE-BOVESPA, para o qual foi reconhecida como uma empresa sustentável.

Quadro 5. Práticas para gestão estratégica quanto à sustentabilidade.

\begin{tabular}{|lccc|}
\hline Práticas para gestão estratégicas & \multicolumn{3}{c|}{ COPEL } \\
\cline { 2 - 5 } & $\begin{array}{c}\text { Demonstração } \\
\text { incorporação }\end{array}$ \\
\hline 3 Metodologia para a & sim & não & em \\
sustentabilidade & & & curso \\
3.3.1 Objetivos do milênio & $\times$ & - & - \\
3.3.2 Eco-eficiência & - & $\times$ & - \\
3.3.3 O pacto global & $\times$ & - & - \\
4 Normas internacionais & - & - & - \\
4.1 Norma AA 1000 & $\times$ & - & - \\
4.2 S A 8000 & - & $\times$ & - \\
4.3 ISO 9000 & - & - & $\times$ \\
4.4 ISO 14000 & - & - & $\times$ \\
5 Os ídices de sustentabilidade & - & - & - \\
5.1 Índice Dow Jones de & - & $\times$ & - \\
sustentabilidade & & & \\
5.2 Índice Bovespa de & $\times$ & - & - \\
sustentabilidade & & & \\
\hline
\end{tabular}

Fonte: Autoria.
O ISE foi desenvolvido em parceria com o International Finance Corporation (IFC) e se assemelha ao índice Dow Jones Sustainability Indexes, implantado na Bolsa de Valores de Nova York (NYSE).

\section{Conclusões}

O presente trabalho tratou dos conceitos e práticas da Responsabilidade Social e Sustentabilidade Empresarial.

O objetivo geral foi o estudo da prática da Responsabilidade Social e Sustentabilidade da empresa COPEL, tendo como instrumento de análise, o Relatório de Gestão de 2005.

No sentido de demonstrar como a COPEL está inserindo tais práticas em sua gestão, foram propostos os seguintes objetivos específicos:

- Identificar e caracterizar os indicadores e relatórios de prestação de contas utilizados na empresa COPEL para medir e apresentar os resultados de sua gestão sustentável.

$\mathrm{O}$ instrumento de análise indicou um grande esforço da COPEL no sentido de inserir-se como empresa de Responsabilidade social empresarial a COPEL adotando o conceito do Instituto Ethos para desenvolvimento de seu modelo de gestão. E, sustentável, implementando ações por meio dos seguintes instrumentos, como plataforma de gestão: como signatária do Pacto Global, como empresa sustentável por meio do ISE- BOVESPA 2005, com a adoção de alguns princípios dos Objetivos do Milênio e Norma AA 1000.

- Identificar e analisar as ações sustentáveis executadas pela empresa.

O principal indicador utilizado para a análise foi a GRI adotada na forma "de acordo". Ao atender a todos os princípios da GRI para elaboração de Relatório, a análise indica que, embora sendo o primeiro Relatório, a COPEL encontra-se em estágio bem avançado na implementação dessas práticas.

Entretanto, o engajamento da empresa na Responsabilidade Social e Sustentabilidade requer que o resultado econômico seja obtido da integração às ações sociais e ambientais.

Os dados coletados a respeito da Responsabilidade Social e Sustentabilidade da forma como estão apresentados, não permitem identificar a integração das ações sociais e ambientais ao resultado econômico.

Ainda que a GRI seja um modelo de evidenciação, as ações nela descritas, ficam limitadas somente a aspectos qualitativos, uma vez que as próprias diretrizes de 2002 não avançaram ainda para esse grau de detalhamento e de comprovação efetiva de resultados que a empresa pretende alcançar neste contexto de desenvolvimento sustentável. 


\section{Referências}

ASSOCIAÇÃO BRASILEIRA DE NORMAS TÉCNICAS. NBR 16001. Rio de Janeiro, 2004.

BEZERRA, R. B. Responsabilidade social corporativa: uma proposta metodológica para orientação de iniciativas. 2007. 141f. Dissertação (Mestrado em Ciência em Planejamento Energético) - Universidade Federal do Rio de Janeiro, Rio de Janeiro, 2007.

BITTENCOURT, C. M. A. A informação e os indicadores de sustentabilidade: um estudo de caso no observatório regional base de indicadores da sustentabilidade metropolitana de Curitiba - ORBIS MC. 2006. 235f. Tese (Doutorado em Engenharia de Produção e Sistemas) - Universidade Federal de Santa Catarina, Florianópolis, 2006.

BUFFARA, L. C. B. Desenvolvimento sustentável e responsabilidade social: um estudo de caso no grupo O Boticário. 2003. 145f. Dissertação (Mestrado em Engenharia de Produção) - Universidade Federal de Santa Catarina, Florianópolis, 2003.

COMISSÃO MUNDIAL PARA O MEIO AMBIENTE E DESENVOLVIMENTO- CMMAD. Nosso futuro comum. 2. ed. Rio de Janeiro: FGV, 1991.

COPEL. Mensagem do presidente. Curitiba, 2006. Relatório Anual. Disponível em: <http://www.copel.com/ relatorio2005/01_01.htm>. Acesso em: 14 dez. 2006.

INSTITUTO ETHOS. Balanço social. São Paulo, 2006. Disponível em: <www.Instituto Ethos.org.br>. Acesso em: 16 abr. 2007.

INSTITUTO ETHOS. Guia para elaboração do balanço social e relatório de sustentabilidade. São Paulo, 2007. Disponível em: <www.Instituto Ethos.org.br>. Acesso em: 23 abr. 2007.
INSTITUTO ETHOS. Guia de compatibilidade de ferramentas. São Paulo, 2005. Disponível em: <www. Instituto Ethos.org.br>. Acesso em: 16 abr. 2007.

INSTITUTO ETHOS. Prêmio Instituto Ethos. Disponível em: <http://www.Instituto Ethos.org.br/ DesktopDefault.aspx?TabID=3343\&Alias=Instituto Ethos\&Lang=pt-BR>. Acesso em: 16 jan. 2008.

INSTITUTO ETHOS. Diretrizes para Relatórios de Sustentabilidade da Global Reporting Initiative (GRI). Coordenação de Fábio Feldemann. São Paulo, 2002. Versão brasileira. Disponível em: <http://www. Instituto Ethos.org.br>. Acesso em: 16 abr. 2006.

LEWIS, S. B. Responsabilidade social e jurídica da empresa. Reflexões sobre o desenvolvimento sustentável. Agentes e interações sob a ótica multidisciplinar. Petrópolis: Vozes, 2005.

ORGANIZATION FOR ECONOMIC COOPERATION AND DEVELOPMENT - OECD. Principles of governance. Paris, 1993.

ORIBE, C. Y. A relação entre a SA 8000 e AA1000 com o marco referencial da ética dos negócios: um entendimento necessário. QualyPro, p.1-23, 2007.

SAVITZ, A. W.; WEBER, K. A empresa sustentável: o verdadeiro sucesso é o lucro com responsabilidade social e ambiental. Rio de Janeiro: Elsevier, 2007.

SILVA, C. L.; MENDES, J. T. G. Reflexões sobre o desenvolvimento sustentável. Agentes e interações sob a ótica multidisciplinar. Petrópolis: Vozes, 2005.

TINOCO, J. E. P.; KRAEMER, M. E. P. Contabilidade e gestão ambiental. São Paulo: Atlas, 2004.

VIEIRA, M. F. F. As Ações em eficiência energética no relatório de responsabilidade socioambiental. In: WORKSHOP PANORAMA E PERSPECTIVAS DA EFICIÊNCIA ENERGÉTICA, 2006, Rio de Janeiro, RJ. Anais... 